\title{
Major Sports Events Logistics and Supply Chain Network Platform Construction and Management
}

\author{
Liu Honghua \\ ShenYang Sport University
}

\begin{abstract}
In this paper, literature, field visits and expert interviews on the status of the supply chain management of large sporting events logistics in-depth analysis to identify the main content of major sports events early, mid and late logistics and supply chain management, to build a large-scale sporting events logistics supply chain network platform, effectively conserve resources, reduce operating costs, improve supply chain efficiencies, to meet the different needs.
\end{abstract}

KEYWORD: Supply chain management major sports events logistics supply chain network platform

With the rapid development of social economy, the world's increasing focus on sports, is growing rapidly year by year. At present, more and more sporting events in the world have been carrying out, whether it is the scale of the game, is being held in the frequency or expanding toward the direction of major sports events. Because the number of major sports events participated in numerous, it has great challenges for major sports events organizers speaking. During the tournament, not only need to arrange personnel, supplies should solve the problem, in order to ensure the smooth progress of the event. Good planning and arrangements of these materials need to build large-scale sporting events logistics supply chain network platform.

\section{MATERIAL FLOW}

Material flow is to point to in order to meet the requirements of customers for materials, goods, services, cash, and related information from origin to consumption of high efficiency, low cost flow and storage of the planning, implementation and control of process. Logistics include not only about the production process of all tangible objects, such as raw materials, facilities, etc., also includes all the flow of material within organizations, monitoring items and information. As shown in Figure 1.

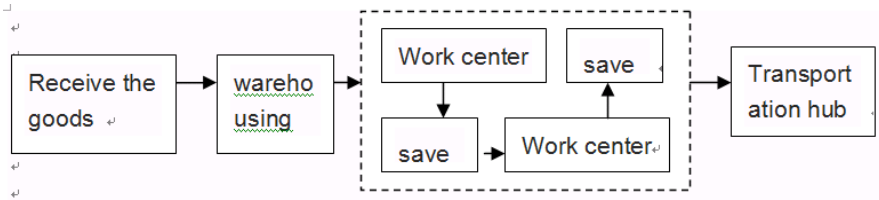

Figure 1 - The organization Material flow

\section{SUPPLY CHAIN MANAGEMENT CONNOTATION}

Supply chain is the supplier, manufacturers, distributors and retailers and final consumers as a whole chain for effective integration, to achieve a competitive advantage throughout the chain. As shown in Figure 2.

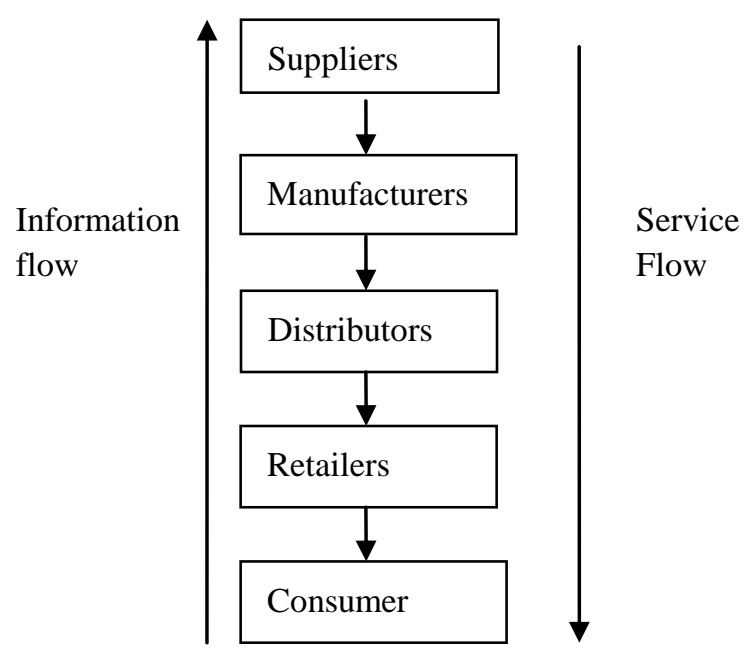

Figure2 - Supply chain systems

Supply chain management is the essence of suppliers, manufacturers, distributors and retailers to integrate and optimize all aspects of business efficiency, reduce costs, efficient operation, enhance the value of the supply chain.

In the actual operation of the process, one is by the manufacturer to promote their products to 
distributors and retailers, in this way, manufacturers are passive;

Another is the role by the manufacturer directly through advertising and other means to consumers, the initiative to find the product by the consumer, that is, through the retailer to the distributor and then to the manufacturer's process, in this way, manufacturers are in a dominant position. As shown in Figure 3.

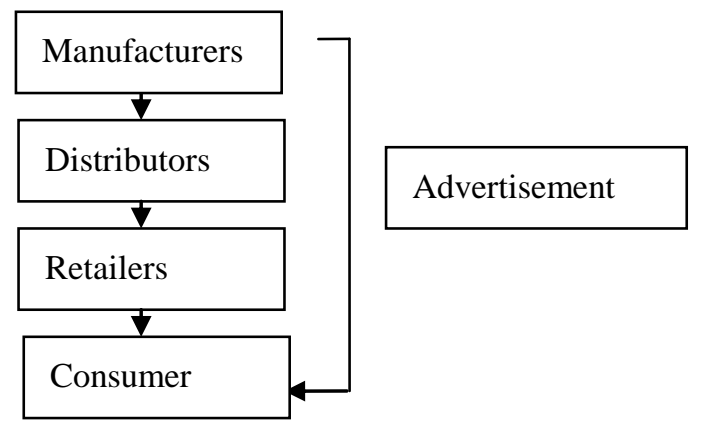

Figure 3-Supply chain systems

\section{MAJOR SPORTS EVENTS LOGISTICS SUPPLY CHAIN NETWORK PLATFORM CONSTRUCTION AND MANAGEMENT}

Major sports event monitoring and management is the purpose of supply chain network platform to build major sports supplies scientific and reasonable allocation. Supply chain network platform mainly includes mage-sport events center management platform, regional logistics center management system, relevant government departments to the business management system, logistics service providers, business management system, five most of the supplier management system. As shown in Figure 4.

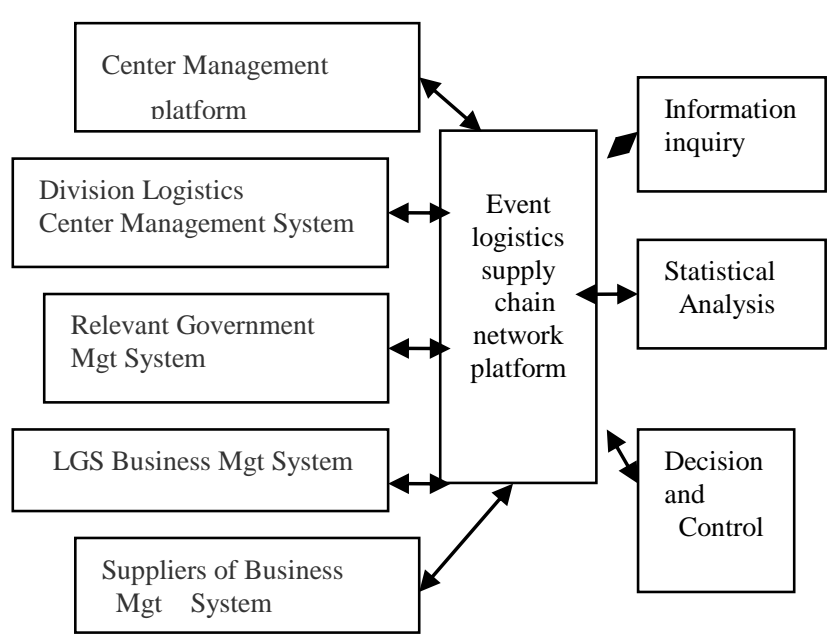

Figure 4- Major sports events logistics supply chain network platform

\section{1 Center management platform}

Center management platform is for large sports supplies scheduling, management, control, monitoring and tracking management. During the event, due to the large amount of information for each sector, center management platform, the information of the supply chain to carry on the summary, and information collection and analysis, the results sent to each department, make other departments in a timely manner to understand information, facilitating resource supply decisions. This requires a lot of supply chain management and data information collection and sorting talents. And according to the statistics, this kind of talent is relatively lack, most researchers from outside the body specialized student.

Center management platform from the technical structure can be divided into three parts, namely data management platform, portal service platform, collaborative work platform.

Portal platform combined with the client terminal, for different customers with international standards or personalized information service, make the terminal consumer at any time and at any place, by any facilities can be connected to the portal platform, to achieve major sports event supply chain information service platform.

Collaborative work platform is to bond connection portal platform and business systems. It is the request of the portal platform to send to the corresponding business system, and the business system to feedback the information in a timely manner to the portal platform.

Data management platform is to provide data storage system. It is not only for major sports events of all kinds of business information collection and sorting, and analyze these data and finishing to the portal platform.

\subsection{Regional logistic cs center management system}

Regional logistics center management system is to allocate resources and establish the system of division. This system will have on the major sports event during the summary and analysis of all kinds of information, real-time monitoring, to ensure that the resources in a timely and reasonable matching, and through the visual and intelligent way of information feedback. Regional logistics center management system consists of forecasting, inventory management, scheduling, real-time tracking and monitoring, venue management and video of the seven modules.

\subsection{Relevant government departments to the business management system}

The establishment of the relevant government departments to the business management system is 
mainly to relevant government departments in a timely manner to understand the pre-match resources situation, understand all kinds of important information, is advantageous for the from on macroscopic control and management. Event occurs during a variety of uncertain events, need to keep information flowing with related government, in a timely manner to solve various problems encountered, and events.

\subsection{Logistics service provider business management system}

Logistics service provider business management system is specified by the ocog supplier business management system, its real-time connected to the center management platform, to ensure reasonable supply of resources during the event.

\subsection{Supplier business system}

Supplier business system with major sports event logistics information platform to keep information links, supplies demand information in time, follow up and decision making.

During the large-scale sports event, need to forecast product demand for contestants in a reasonable manner to ensure timely supply. Therefore, as the supplier need to be: on the one hand, to ensure to meet consumer demand for products, on the other hand to ensure products can be quickly and timely sent to the hands of consumers, reduce inventory. Often, large sports goods demand forecast according to the ticket situation often, teams of workers, the field staff as well as the nature of the product and features to predict, determine the material reserves and management mode. But because of various sports athletes, event staff, audience is different, this will bring competition product demand forecast difficulties, such as the Beijing Olympic Games, the national games held in liaoning.

Events during the consumers' satisfaction with the demand for products in a certain extent determines the competition success. Because of the large sports goods often appear out of stock, inventory, or inadequate or substandard products, lead to competition for consumers in event evaluation. Therefore, event supplier can use comprehensive inventory check or cycle inventory replenishment strategy to adjust and manage products, ensure the supply of products.

Comprehensive inventory strategy refers to the enterprise every once in a while just check inventory at a time, if the inventory level, B or B enterprise gives orders. If check inventory is I, the enterprise is the quantity of goods (E - I). If you examine the inventory is greater than $\mathrm{B}$, enterprises do not need to send the order. This strategy, the examination time $\mathrm{t}$, the maximum inventory order point $\mathrm{B}$ and $\mathrm{E}$ are fixed, and the order time and quantity of goods is changing. As shown in Figure 5.

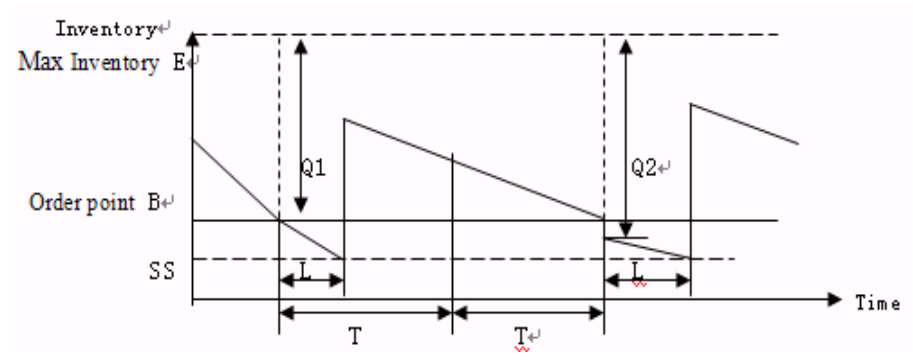

Figure 5 Change in inventories

Cycle check inventory replenishment strategy is also called the regular check inventory strategy or periodic inventory control strategy, is refers to the enterprise needs to check the inventory every once in a while, and issue orders, if the actual inventory when the check is $\mathrm{I}$, then the quantity of goods for (E - I). This strategy, the inspection cycle period $t$ and the maximum inventory order $\mathrm{E}$ is fixed, while the reorder point and order quantity is changing. As shown in Figure 6.

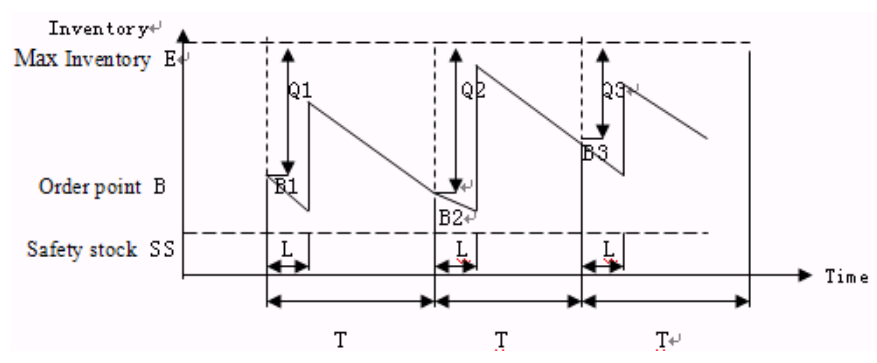

Figure 6 Change in inventories

The advantage of this strategy is due to the regular inspection can reduce check and record the number of people and work. All kinds of inventory to make regular orders at the same time, the less the order frequency, reduce the order cost and transport cost, can get more quantity discount.

The disadvantage of this strategy is not grasp the dynamic inventory at any time, when there is a demand for abnormal situation, may produce out of stock. Because of the safety stock is more, companies need to meet the order cycle and the change of demand during lead time, lead to storage cost. If the less order cycle inventory decline, also need to place an order, that result in an increase in the order amount.

This strategy is suitable for the materials storage cost and shortage cost is low, from the same material supply charges to order a variety of different materials can make the order and transport has a larger decline in space of class $\mathrm{C}$ stock material.

Through the above analysis, it can be seen that large sports building and management of supply chain network platform can well solve the event supplies scientific and reasonable allocate, cost 
savings, improve efficiency. At the same time, in order to better provide personalized, customized service, improve the portal management system, increase the channels of communication with consumers, to ensure access to a variety of feedback of consumer information, and put forward the solution in the first time.

\section{SAFEGUARD MEASURES}

\subsection{For major sports events the efficient operation of} the logistics supply chain network platform and major sports organizations need to do a good job of the following:

Ensure the component of supply chain logistics information system modernization level Major sports events require of the real-time monitoring and management of information, each component that requires organizations to strengthen logistics supply chain information system deployment and upgrades, to ensure the safety during the event logistics supply. Namely select qualified higher organization cooperation, this is also part of the enterprise to become one of the main reason for the major sports event partners.

\section{2 have talented person of logistics supply chain management}

At present, the lack of logistics supply chain management talents in the market. In order to promote the development of the major sports event, need to cultivate a group of people who master the sporting event and logistics supply chain management. Cultivating way can be done by extending the course content. This is no longer limited to the higher sports colleges and universities, for the opening of a sports management class specialized subject in colleges and universities by adding the corresponding courses to achieve the goal of talent cultivation.

\section{3 real-time tracking sports consumer demand changes}

Sports organizations need to understand the sports consumer demand change, and sports consumer demand as the core, in order to carry out activities. Large sports events organization according to consumers' intention, change the way that the operating methods, such as through on-site activities display, micro letter, weibo, QQ and so on different ways to attract sports consumer interest and attention, increase their engagement and enthusiasm, improve the influence of the sports events.

\section{REFERENCES}

[1] Chen XiaoDong. Analysis and optimization of value-added potential of supply chain management. Logistics technology. 2014 (01).

[2] Guo HongTao, Zhang Zhonglou. Construction of largescale sports event logistics information platform and information security. Logistics technology. 2013 (07) 